light increased in frequency and brilliancy, and at $\mathrm{I} I .25$ they might be described as broad flashes overspreading a large part of the northern half of the sky, always travelling upwards, and sometimes passing the zenith. The main body of streamers had by this time mostly faded, after going through an extraordinary series of charges which I found it quite impossible to record. Every minute or two new rays would strike up to the zenith, or sometimes beyond, and every now and then a portion of an older ray would suddenly shine out with a kind of phosphoric light.

The display now rapidly faded, and though at II.35 and again about II.45 there were minor reappearances of rays, the aurora seemed to be near its end, and I returned home.

The brightness of the phenomenon was somewhat delusive; for when a superb corona of rays covered the northern sky, I could only just read my watch by its light, and could not read what I endeavoured to write down on paper. The light was either white or of a greenish yellow tinge. There was no trace of the redness or other colours seen on other occasions.

By very good fortune I was able to watch the aurora of the next night (August 13) under the most favourable possible circumstances, namely, while steaming down the Christiania Fyord, in the steamship Angelo, during a beautiful calm evening. The aurora began at Io.20 p.m. with a very faint uniform arch, or rather line of white light, appearing $8^{\circ}$ or $10^{\circ}$ above the horizon, with difficulty distinguished from the twilight. This soon faded away entirely; but at 10.35 reappeared as a very distinct luminous arch, separated by a dark space from the twilight. Some slight signs of rays now also appeared.

At 10.45 the arch seemed to be rising somewhat, without ever attaining a height of more than about $15^{\circ}$. The lower edge became indented by ray-like notches. There was a tendency to the formation of streamers at the flanks. At 10.50 a fine single ray shot up from the horizon right through the arch, at $10^{\circ}$ to west of true north. Streamers also began to appear above the arch, and especially at its eastern end ; but the streamers were in no way comparable to those of the previous night. The arch now began to lose its previous regular form, and to go through a remarkable series of gradual changes and contortions, which it is impossible to describe. By degrees the eastern end became incurved in the manner of a folded curtain (like the pictures of auroras in the Polar regions which we see in books), and a few fragments of rays tended to form an inferior arch.

For more than an hour the light of this aurora was steady; but about II.30 p.m. pulsations first began to appear faintly, soon increasing in frequency and width. As the pulsations grew the arch almost insensibly disappeared, but patches of light and fragments of rays occupied the sky above where the arch had been, and were every instant lighted up, as it were, by the passing coruscations. These flashes of light became more and more frequent, following each other every second, or even several times in a second, so as to produce at last a kind of rustling or dancing appearance. They were most intense upon the rays and patches, but were not confined to them. At 12.30 the display was failing, the waves being less frequent. At I a.m. there remained only a few irregular patches of faint, steady light, with occasional flashing waves. The light was again white, or greenish yellow. On neither occasion did the aurora secm to have the slightest relation to the ordinary vaporous clouds of the atmosphere, nor did the dark space beneath the arch seem to be more than might be explained as the effect of contrast.

Mr. Thomas Bennett, who is well known to all Norwegian travellers, and has resided many years in Christiania, informed me that the aurora of the I2th was probably the finest he had ever secn among the many grand displays which occur in Norway. Though I have witnessed several fine auroras, including some of those seen in the United States in August and September, I859, and two fine displays of the Aurora Australis (September I4 and I6, I854), I cannot call to mind that I ever saw coruscations or waves of electric light at all approaching those seen at Christiania on this occasion. The books say comparatively little about these coruscations, nor do the letters in NATURE, vol. xxii. p. 36r, mention them as seen in England. Yet they probably represent the most important part of the phenomenon, the active discharge of electric energy.

I neither saw nor heard anything in Norway of an aurora on the night of August II. About the dates I give there can be no possible mistake, because the steamboat from Christiania to Hull departed as usual on Friday evening (August 13 ). The times mentioned are the local times by the public clock at the Christiania University Buildings. W. STANLEY JEVONS

P.S.-The above account was mostly written a few days after my return to London. according to notes taken at the time. I print it now for what it may be worth. After thinking the matter over for three months, and comparing the auroral coruscations above described with the exquisite discoveries of Mr. Crookes, taking into account also some remarks in the article on auroras in the new edition of the "Encyclopædia Britannica," I venture to make the suggestion that these coruscations arise from highly tenuous matter (in what $\mathrm{Mr}$. Crookes calls the radiant state) projected through the higher parts of the atmosphere. It is not possible by words to give an impression of such a phenomenon in the least degree approaching to that naturally acquired by watching it under favourable circumstances for several hours. My belief is, that during the auroras described, puffs, as it were, of radiant matter were discharged at a great elevation above the earth's surface, and the luminosity of these puffs perhaps arises from conflicts between the projected molecules and those already spread about the almost vacuous space. The arch and most of the streamers probably belong to a lower, though still a very high part of the earth's atmosphere, but certain of the streamers, as well as patches of luminous matter seen on the night of the 13 th, certainly exist in the lofty regions through which the radiant matter is projected. The explanation of the streamers must probably be approached through that of the coruscations, but they are effects of a very different kind.

November 22

\section{THE INFLUENCE OF A TUNING-FORK ON THE GARDEN SPIDER}

HAVING made some observations on the garden spider which are I believe new, I send a short account of them in the hope that they may be of interest to the readers of NATURE.

Last autumn, while watching some spiders spinning their beautiful geometrical webs, it occurred to me to try what effect a tuning-fork would have upon them. On sounding an A fork and lightly touching with it any leaf or other support of the web or any portion of the web itself, I found that the spider, if at the centre of the web, rapidly slews round so as to face the direction of the fork, feeling with its fore feet along which radial thread the vibration travels. Having become satisfied on this point, it next darts along that thread till it reaches either the fork itself or a junction of two or more threads, the right one of which it instantly determines as before. If the fork is not removed when the spider has arrived it scems to have the same charm as any fly: for the spider seizes it, embraces it, and runs about on the legs of the fork as often as it is made to sound, never seeming to learn 
by experience that other things may buzz besides its natural food.

If the spider is not at the centre of the web at the time that the fork is applied, it cannot tell which way to go until it has been to the centre to ascertain which radial thread is vibrating, unless of course it should happen to be on that particular thread or on a stretched supporting thread in contact with the fork.

If when a spider has been enticed to the edge of the web the fork is withdrawn and then gradually brought near, the spider is aware of its presence and of its direction, and reaches out as far as possible in the direction of the fork ; but if a sounding fork is gradually brought near a spider that has not been disturbed, but which is waiting as usual in the middle of the web, then instead of reaching out towards the fork the spider instantly drops-at the end of a thread of course. If under these conditions the fork is made to touch any part of the web, the spider is aware of the fact and climbs the thread and reaches the fork with marvellous rapidity. The spider never leaves the centre of the web without a thread along which to travel back. If after enticing a spider out we cut this thread with a pair of scissors, the spider seems to be unable to get back without doing considerable damage to the web, generally gumming together the sticky parallel threads in groups of three and four.

By means of a tuning-fork a spider may be made to eat what it would otherwise avoid. I took a fly that had been drowned in paraffin and put it into a spider's web and then attracted the spider by touching the fly with a fork. When the spider had come to the conclusion that it was not suitable food and was leaving it, I touched the fly again. This had the same effect as before, and as often as the spider began to leave the fly I again touched it, and by this means compelled the spider to eat a large portion of the fly.

The few house-spiders that I have found do not seem to appreciate the tuning-fork, but retreat into their hidingplaces as when frightened; yet the supposed fondness of spiders for music must surely have some connection with these observations, and when they come out to listen is it not that they cannot tell which way to proceed?

The few observations that I have made are necessarily imperfect, but I send them, as they afford a method which might lead a naturalist to notice habits otherwise difficult to observe, and so to arrive at conclusions which I in my ignorance of natural history must leave to others.

Physical Laboratory, South Kensington

\section{THE MINERALOGICAL SOCIETY OF GREAT BRITAIN AND IRELAND}

THERE was a time, now almost beyond the memory even of the oldest inhabitant, when the stillness of our learned halls was unbroken by the wrangle of contending geologists, when the science of geology could not be said yet to exist, when those who occupied themselves with stones found a congenial atmosphere of solemnity in the quiet domain of crystallography, whence with the boldness of adventurers they made little excursions into the more open and dangerous waters of chemistry. Days of slumberous peace as they now seem to one who turns over the ponderous dusty pages in which their records are duly chronicled! To the mineralogist of those days the interest and importance of rock-masses was measured by their richness or poorness in mineral specimens. Surrounded by his cases of minerals-the reward of years of patient toil and judicious expenditure, with what tender interest would he survey his treasures! We knew him in old times, yea and loved him. Enthusiastically would be describe how he had contrived to secure that priceless unique crystal; how day after day he had searched the rocks in vain, till at last one lucky stroke of the hammer laid open that magnificent druse; how he had bought that matchless group from a sailor who used it to keep down the lid of his tobacco box. Kindly too he was, and all the more if you took interest in his favourite pursuit. Ask him to tell you the difference between two resembling minerals, and he would launch out with evident relish into his "external characters." Lovingly would he handle the specimens, as if they were the children of his old age. Eagerly would he descant upon the difference between "lamellar distinct concretions"; how some were "indeterminate curved lamellar," others were "fortifications-wise bent." And then would follow the whole string of characters-" semi-hard," "not particularly diffcultly frangible," "supernatant," "pretty cold," "not par ticularly heavy," between "aurora-red" and "hyacinthred," or between "mountain-green" and "celandinegreen." Such jargon it seemed to youthful ears! One could not but admire indeed its methodical precision, but the questions ever forced themselves on one's mind-What is the living truth underlying it all? Were minerals really created merely as a basis for our old friend's systems of classification? Or can they not be made to yield up some intelligible record of their own history and of the planet of which they form a part?

When the discoveries of William Smith drew off the attention of students to the marvels revealed by stratigraphical geology, mineralogy rapidly sank into neglect in this country. By a curious revulsion of opinion rocks were now appraised as of importance in proportion as mere mineral specimens were absent from them, for where these occurred organic remains were usually not to be looked for; and organic remains now took the place of minerals. Men who would formerly have trudged cheerfully a whole day with a I4-lb. hammer on their shoulders to secure a few minerals were now to be seen as enthusiastically hunting for ammonites, gryphaeas, belemnites, echini, fossil fishes, and other buried treasures of the stratified formations. Unmeasured was the scorn of the veteran mineralogist for this new-fangled pursuit. To neglect such attractive objects as minerals, with their exquisite forms and colours, for the dingy and fragmentary relics of extinct whelks, lobsters, and other pre-adamite vermin seemed to him an utterly unaccountable form of madness. And so his beloved cabinet became dearer to him than ever. In its quiet retreat he lived with his specimens in the past, and allowed the strong rising tide of palæontology to rush and roar past him unheeded.

But cycles appear in scientific as in political opinion. For some years past there has been a growing conviction that palæontology has had a long enough monopoly of power in the geological commonwealth, and that the mineral ogical side of the science has in this country been unduly neglected and discouraged. The attention now bestowed among us upon petrographical research is a pleasing proof of the reality and steady progress of this reaction. Another token of the same change is supplied by the foundation and encouraging growth of the Mineralogical Society of Great Britain and Ireland. This society was instituted in the early part of the year 1876 . It counts among its members a large and increasing number of the best geologists in the three kingdoms. But its operations are carried on so quietly and unostentatiously that its work and aims are probably not yet so widely known as they deserve to be. A body gathered under the leadership of Sorby and Heddle is one which may count on support from all to whom the advancement of mineralogy and mineralogical geology among us is an object of interest. As a rule our scientific societies are bodies with a local habitation, gathering most of their effective members from the district in which their rooms are placed. But the Mineralogical Society, as its name denotes, embraces the whole United Kingdom. It has no buildings of its own nor any one special home. Its meetings, like those of the British Association on a large scale, are 